\title{
PROTECCIÓN Y CONSERVACIÓN DE LA FLORA EN LA COMUNIDAD VALENCIANA
}

\author{
Ascensión Padilla Blanco \\ Departamento de Análisis Geográfico Regional \\ Universidad de Alicante
}

\section{RESUMEN}

La localización geográfica de la Comunidad Valenciana (C.V.) le confiere unas características climáticas particulares que añadidas a su variada litología, disposición y estructura del relieve, red hidrográfica y zonas húmedas, determinan una variada flora. La importancia de su diversidad no sólo radica en el elevado número de táxones, sino también en el de endemismos, localizados en su mayoría en roquedos, acantilados, matorrales xéricos y terrenos baldíos; sectores que, por tener una valoración perceptiva muy baja, pueden ser fácilmente objeto de alteraciones por parte del hombre.

Desde finales del siglo veinte, con motivo de la entrada en la U.E., el aparato legislativo español tiene un amplio desarrollo en protección del medioambiente, donde se incluye desde la escala de los espacios protegidos hasta el de la especie.

El desarrollo económico, sobre todo desde los años setenta, ha ido parejo a una intensa ocupación del suelo en la C.V., especialmente por la actividad turística centrada en el sector litoral, lo que ha desembocado en la reducción de poblaciones florísticas y en un aumento del riesgo de desaparición de algunos táxones que son raros o endémicos del ámbito valenciano. Por este motivo, se realiza una revisión de la legislación cuyo fin es proteger estos espacios, para observar las carencias existentes y hacer una llamada de atención en su puesta en práctica.

Palabras clave: legislación ambiental, espacios protegidos, diversidad florística, endemismos, flora amenazada, Comunidad Valenciana.

\section{ABSTRACT}

The weather features, variety of litology, structure of the relief, hidrographic net, humity areas in the Comunidad Valenciana (C.V.) determine a diverse flora. The importance of this diversity not only consists in the sizeable number of taxons but also of the endemisms localized in rocky places, cliffs, arid thicket and uncultivated lands. As all of these areas have a negative valoration, they are easily alterated by human action. 
The spanish legislation counts with a wide development in the environment protection from the last years of the twenthieth century caused of the entrance in the U.E., where it is included the protected areas and the species.

The economic development, more than ever from the seventieth, has been accompanied with an intense occupation of the ground in the C.V., specially by the touristic activity concentrated in the seaboard, which has produced a reduction in the vegetal poblations and increament of the risk of disappearance of rare or endemic flora in the C.V. That's why, it is done a revision of the legislation in this paper that has as assigment the protection of these areas, to observe the lacks and to attract attention in its practice.

Key words: environmental legislation, protected areas, floristic diversity, endemisms, flora in dangered, Comunidad Valenciana.

\section{Introducción}

La riqueza, variedad y valor de la flora de la Comunidad Valenciana hace necesaria una revisión de las leyes y organismos que hagan mención directa o indirecta a la necesidad de protegerla, desde una escala internacional y europea hasta la del propio territorio valenciano. Es evidente la importancia que en las últimas décadas adquiere la protección del medio ambiente. Ésta se manifiesta en la legislación y en una mayor concienciación social, al margen de los intereses políticos que pueda haber detrás de todo ello.

Para analizar la situación legislativa actual que afecta a la flora y a la cubierta vegetal valencianas, es preciso tener en cuenta que ambas forman parte de un sistema mayor compuesto por otros elementos abióticos, bióticos y antrópicos, al que podemos denominar geosistema. Su funcionamiento se basa en las relaciones entre estos componentes, que mantienen un continuo equilibrio, de modo que si uno de ellos sufre una alteración se produce, de manera más o menos rápida, una reacción en cadena, al tiempo que un restablecimiento natural de dicho equilibrio. Con el desarrollo tecnológico de la sociedad, fundamentalmente desde el siglo pasado, tiene lugar «la transformación a gran escala del espacio y la aculturación del paisaje natural mayor en intensidad y extensión que la lograda en milenios de historia» (DE TERÁN, 1966); la intervención humana en el medio supera a la capacidad natural de ajuste del geosistema. Ante esto, el hombre ha intentado buscar soluciones que han desembocado en un «equilibrio antropogénico» y que, la mayoría de las ocasiones, han sido adoptadas a posteriori del impacto, es decir, con un carácter curativo. Son, sin embargo, las medidas preventivas las que deberían prevalecer, dentro de las cuales se incluye el cuerpo legislativo. Tanto unas como otras, han de tener en cuenta las relaciones existentes entre la flora y el resto de componentes de dicho sistema.

Las primeras leyes referidas a la conservación y protección del medio natural en España conciernen a espacios naturales y se remontan a principios del siglo pasado; aunque en otros países datan del siglo XIX, como es la declaración del primer parque nacional de Estados Unidos en 1872, el de Yellowstone. Desde entonces y hasta las últimas décadas del siglo veinte, se observa un cambio en los criterios, pasando de un ensalzamiento de los valores estéticos, a entender el medio ambiente como un recurso, desde un punto de vista economicista y, finalmente, se insiste por su protección y por la conservación de la biodiversidad ante el paulatino deterioro al que se ve sometido. 
El conjunto legislativo que afecta a la flora y a la vegetación, está tratado desde dos vertientes: el urbanismo o planificación territorial y el medioambiente. En la primera, el aspecto medioambiental se recoge como un elemento más del territorio, de forma sesgada y nula a escala de detalle; es decir, en el caso de la flora endémica, rara o amenazada, no existe ninguna normativa de protección, debido, por lo general, a que estas especies ocupan áreas de escasas dimensiones y suelen coincidir con zonas consideradas perceptivamente menos atractivas y fácilmente calificables como urbanizables, como puede ser un matorral ralo y abierto sobre margas y yesos triásicos (MATEO, G. y CRESPO, M.B., 1990), o donde los intereses económicos imperan sobre cualquier otro y pueden ser objeto de alguna intervención urbanística, por ejemplo en las zonas de litoral. Si comparamos los diferentes hábitats donde se localizan las plantas endémicas valencianas (Cuadro 1), éstas predominan en matorrales bajos, como pueden ser tomillares o salviares, mientras que es mínima su representación en formaciones vegetales más desarrolladas, caso de un carrascal.

La estructura del presente trabajo parte de la distinción de estos dos cuerpos legislativos y de cómo cada uno, a diferentes escalas, trata la protección y conservación de la flora valenciana.

\section{La protección de la cubierta vegetal en la planificación y ordenación del territorio}

La ordenación del territorio valenciano se rige por la Ley 6/1989 de 7 de julio, entre cuyos objetivos se encuentran los de la gestión de los recursos naturales y la protección del medio ambiente, preservar las condiciones ambientales y elementos naturales de acciones agresivas, conservar el patrimonio paisajístico y fomentar la regeneración natural o asistida de las tierras dejadas de cultivar. Para cumplir dichos objetivos, se sirve de los instrumentos de planificación, en los que se reconoce la necesidad de realizar un estudio del medio físico donde se analizaría cada uno de los elementos que componen el paisaje natural, además de un inventario y localización de espacios naturales e indicación de medidas preventivas y pautas a seguir para su conservación y gestión. En el régimen del suelo, se establecen tres categorías con nivel de protección legal ante la actividad urbanística: Patrimonio Rural, por presencia de elementos topográficos, masas vegetales, espacios naturales o yacimientos arqueológicos; Medio Ambiente Rural, referido a aquellas zonas con valor paisajístico, eco-

Cuadro 1

DISTRIBUCIÓN DE LAS PLANTAS ENDÉMICAS VALENCIANAS IBEROLEVANTINAS SEGÚN SU HÁBITAT ÓPTIMO

\begin{tabular}{|l|c|}
\hline Hábitat & Porcentaje (\%) \\
\hline Roquedos verticales, cingles, cintos & $\mathbf{1 8 . 7 0}$ \\
Ambientes pedregosos no verticales & 17.39 \\
Pastizales, herbazales y baldíos & 16.52 \\
Pastizales muy secos y matorrales bajos & 6.52 \\
Matorrales bajos (tomillares, salviares) & $\mathbf{2 9 . 5 7}$ \\
Saladares, yesares, ambientes salinos & 8.26 \\
Bosques de quercíneas y climax forestales & $\mathbf{3 . 0 4}$ \\
\hline
\end{tabular}

Fuente: Mateo, G. y Crespo, M.B. (1990): Claves para la flora valenciana. Ed. Del Cenia al Segura. Valencia. 
lógico o ambiental que requieran de protección y recuperación; Paisaje, en el que se incluyen los espacios o elementos recogidos en la Ley de Parajes Naturales Protegidos de la Comunidad Valenciana.

Debido a la profusión de edificaciones agrícolas en suelo calificado como no urbanizable que, en realidad, tienen un uso como viviendas de segunda residencia, se promulga la Ley de Suelo No Urbanizable 4/92 de 5 de junio, en la que destacan fundamentalmente tres aspectos:

- el vínculo que establece con otras leyes de ordenación territorial y de medioambiente, en las que se proteja algún espacio;

- la prohibición de clasificar o reclasificar un suelo no urbanizable (SNUrb), que se haya visto afectado por un incendio forestal; $y$

- la figura de Parajes Naturales Municipales, para aquellas zonas dentro del territorio municipal que, por su valor natural, requieran su protección y mejora, con lo que ese espacio pasaría a ser clasificado como SNUrb de especial protección y estaría ordenado o gestionado por un Plan Especial de Protección. Esta figura será recogida dos años más tarde por la Ley de Espacios Naturales Protegidos de la Comunidad Valenciana.

En 1994, se promulga la Ley Reguladora de la Actividad Urbanística (6/1994 de 15 de noviembre), en cuya sección cuarta se menciona la necesidad de elaborar un Catálogo de Bienes y Espacios Protegidos, no sólo de bienes inmuebles o espacios con interés cultural, artístico, entre otros, sino también paisajístico y botánico, entre los que se incluyen los ya sujetos a la legislación de patrimonio cultural o medio ambiente.

Será mencionado nuevamente este Catálogo, por un lado, en el capítulo III de la Ley del Patrimonio Cultural valenciano (4/1998 11 de junio), donde se establece que los bienes son tres: la figura de Jardín Histórico, los elementos incluidos en el Catálogo y los concernientes a patrimonio arqueológico, museos; y por otro, en el capítulo VIII del Reglamento de Planeamiento de la Comunidad Valenciana (201/1998 de 15 de diciembre), donde se establece que todo Plan General debe incluir uno, aunque también puede aprobarse como Planes independientes, documentos Especiales, Parciales o de Reforma Interior. Además se especifican tres niveles de protección para estos espacios: integral, parcial y ambiental.

Tras esta breve enumeración de leyes urbanísticas y de planeamiento con cierto sesgo medioambiental, es evidente la escasa protección de la flora, aunque sí de paisajes o masas vegetales, como es la figura de los Parajes Naturales Municipales, pero que, al fin y al cabo, se refiere a un espacio protegido y no a especies en concreto que estén amenazadas o tengan un interés florístico importante.

Por último, es necesario hacer mención de una herramienta o instrumento de planeamiento, creado con el fin de regular cualquier intervención humana en el medio y prevenir su posible impacto: Evaluación de Impacto Ambiental (2/1989 de 3 de marzo y modificada por RD/Ley 9/2000 6 de octubre). Sin embargo, los estudios que acompañan a toda EIA han quedado relegados, en muchas ocasiones, a un mero trámite administrativo, restándole importancia, a lo que cabe añadir que es la misma persona o empresa que ejecuta el proyecto quien realiza el estudio o contrata a otra para que lo haga. Por otro lado, no se mencionan todas las actividades que deberían de requerir una EIA obligatoria y no todas las que lo exigen se recogen en esta ley, sino que son enumeradas en otras, lo que incrementa la dificultad en su conocimiento y aplicación (CANCER, 1995). 


\section{La protección de la cubierta vegetal en la legislación medioambiental}

Desde la entrada en 1986 de España en la Unión Europea (UE), entonces Comunidad Económica Europea (CEE), la protección del medioambiente estará más presente en nuestra legislación, como consecuencia de la ratificación de convenios internacionales o trasposición de leyes promulgadas por la Directiva Europea. De hecho, ese mismo año, España suscribe el primer acuerdo para la conservación de flora y fauna de Europa en el Convenio de Berna. Coincide esta fecha con un cierto «boom» del tema medioambiental a escala mundial, debido a la aparición de problemas relacionados con la contaminación atmosférica, de suelos y desaparición de especies. Surge, por lo tanto, un nuevo concepto: la biodiversidad, por el que se entiende a la Naturaleza como a un geosistema, cuyo equilibrio se ha roto y es preciso restablecer. La respuesta política a escala internacional no se produce hasta la siguiente década con la Conferencia de las Naciones Unidas sobre el medio ambiente y el desarrollo en Río de Janeiro, donde se redacta un Convenio sobre la diversidad biológica, que España firmará ese mismo año, en 1992. Posteriormente, existen otras iniciativas, pero siempre como compromisos políticos sin trascendencia; por ejemplo la Carta de las Nacionalidades y Regiones Europeas por el Medio Ambiente (Carta de Valencia) de 1995, o como informes de la situación actual y expectativas de futuro, dentro de los que destaca el redactado por la Agencia Europea del Medioambiente (AEMA): El medio ambiente en la UE en el umbral del siglo XXI: evaluación del desarrollo de la calidad ambiental en la UE hasta el 2010. La repercusión en el ámbito nacional será doble: por un lado, el RD para contribuir a garantizar la biodiversidad mediante la conservación de los hábitats naturales y de la fauna y flora silvestres (1997/1995 de 7 de diciembre) y por otro, la redacción de la Estrategia española para la conservación y el uso sostenible de la diversidad biológica, informe interesante sobre la situación nacional y las posibles actuaciones futuras; aunque su difícil puesta en práctica, desde el punto de vista económico, lo convierte en una utopía.

\subsection{Protección de áreas de especial interés}

\subsubsection{Conservación o restauración de medios}

La protección de la cubierta vegetal no sólo se efectúa con carácter preventivo a través de la promulgación de leyes, que, por otra parte, es lo más correcto, sino que también es necesario hacerlo de modo curativo en aquellos casos donde el medio haya quedado alterado por causas naturales (como pueden ser incendios y sequías) o por el hombre; dentro de estas últimas, se incluyen las políticas medioambientales encaminadas a la restauración de esos medios alterados.

A escala internacional, España firmó el Convenio Europeo del Paisaje en octubre del año 2000, para promover la protección, gestión y ordenación de los paisajes, en los que se incluye todo tipo de espacios, desde el urbano al rural, zonas marítimas, ... En el ámbito nacional, el organismo encargado de la conservación y restauración de medios es la Comisión Nacional de Protección de la Naturaleza del Ministerio del Medio Ambiente que lleva a cabo un programa de aprobación anual de Protección y Mejora del Medio Natural cuyas líneas de actuación son los incendios forestales, conservación de espacios protegidos, bosques en zonas rurales y gestión sostenible de montes públicos. También dependiente de este Ministerio, se creó en 1997 el Servicio de Protección de los Montes contra Agentes Nocivos 
(SPCAN), con el fin de realizar un seguimiento del estado de las masas forestales, para evitar cualquier desequilibrio que les pueda afectar (plagas o incendios) interviniendo con técnicas selvícolas y biotecnológicas.

En lo que se refiere a la protección vegetal, a escala nacional, no existe una legislación forestal en concreto, sí una serie de Reales Ordenanzas y Reales Decretos que se han ido modificando en las últimas décadas, en parte obligado por las directivas de la UE y por sanciones o críticas recibidas, y que dirigen sus objetivos hacia la conservación y protección de los montes. Uno de los resultados de este cambio es el informe Estrategia Forestal, presentado en enero de 2000 en Bruselas, en el que se evidenciaba la contradicción entre la superficie forestal española ${ }^{1}$ y las escasas inversiones efectuadas en este campo, la nula integración entre la política nacional y de autonomías, la necesidad de un Plan Forestal Nacional como paso previo a la Ley Forestal y la creación de un Consejo Nacional de Bosques, recientemente aprobado por RD 203/2000 de 11 de febrero.

Resulta paradójico que ante esta situación, algunas Comunidades Autónomas (CCAA) hayan optado por redactar y promulgar una ley forestal, aunque no exista ese marco legal estatal. Un ejemplo es la Comunidad Valenciana con la ley 3/1993 de 9 de diciembre, así como el posterior Reglamento aprobado por el Decreto 98/1995 de 16 de mayo. De este modo, se crea el Consejo Forestal como órgano consultivo autonómico en esta materia y se establecen como instrumentos de ordenación el Plan General de Ordenación Forestal que regula los instrumentos y criterios de política forestal, y los Programas de Gestión y Mejora Forestal; ambos tendrán en cuenta las Directrices Técnicas básicas para las actuaciones de reforestación o repoblación forestal en la Comunidad Valenciana, aprobadas por la Orden de 3 de mayo de 1995 de la Consellería de Medio Ambiente, entre las que destacan el listado de especies vegetales apropiadas para cada comarca, las condiciones técnicas a seguir para la plantación, y la exigencia de presentar un Proyecto antes de llevarla a cabo, en el que se analicen los rasgos físicos de la zona y, según estos, se exponga y justifique el tipo de actuación.

Ante el importante abandono agrícola observado durante la segunda mitad del siglo veinte en países comunitarios y los problemas añadidos de erosión, pérdida de suelo, ralentización de la regeneración de la cubierta vegetal, sobre todo en el ámbito mediterráneo, el Consejo Europeo establece en el año 1992 un sistema de ayudas a los agricultores que quisieran forestar sus explotaciones agrarias (Reglamento 2078 y 2080); de modo que a partir de esta fecha la Consellería de Medio Ambiente ofrece anualmente reforestar con especies vegetales mediterráneas campos abandonados para dinamizar su colonización natural y, por lo tanto, evitar procesos erosivos. Pese a lo que cabría esperar, esta iniciativa ha tenido un escaso éxito debido a varias razones, como son la burocracia para realizar la solicitud, las condiciones requeridas para poder tramitarla, la escasez de las subvenciones y el compromiso a no poder explotar esas tierras en un plazo mínimo de diez años (HERNÁNDEZ, 1998).

En la restauración de las masas forestales de la Comunidad Valenciana juega un papel importante el Banco de Semillas de la Generalitat Valenciana, puesto que experimenta con especies propias del mundo mediterráneo, pero no sólo arbóreas, sino también del típico

1 La superficie forestal española representa un $51.9 \%$ del total del territorio nacional. Se trata del porcentaje más elevado de los países de la UE, sólo superado por Suecia y Finlandia con un $74 \%$. 
matorral camefítico, como pueden ser romero, tomillo, ...; rompiendo así con la política tradicional de las repoblaciones monoespecíficas de pino. Esta línea de actuación está apoyada por la emisión de órdenes de la propia Consellería de Medio Ambiente, dirigida a potenciar los aprovechamientos agroforestales y el cultivo con fines comerciales de plantas aromáticas, medicinales y condimentarias en campos abandonados y, de este modo, dinamizar las áreas rurales.

\subsubsection{Hábitats naturales}

El primer acuerdo internacional para la conservación de flora y fauna que afecta a la UE es el Convenio de Berna, plasmado en la Directiva de Hábitats (92/43/CEE de 21 de mayo) que recoge en dos anexos las especies estrictamente protegidas y las que se incluirán en la futura Red Natura $2000^{2}$. El proceso para la constitución de esta red ecológica consiste en la elaboración de un listado de áreas de interés biológico o Lugares de Interés Comunitario (LICs), presentado por cada país miembro, y que antes del 2004 serán declarados como Zonas Especiales de Conservación o ZECs (CRUZ y SUCH) y Zonas de Especial Protección para Aves (ZEPAs). España es el país que solicita una mayor superficie con interés ecológico para ser incluida en la mencionada lista europea (Cuadro 2); petición que se justifica por ser uno de los países con más elevada variedad de hábitats (Cuadro 3), calificativo reconocido en la Directiva 92/43, y por poseer la más alta diversidad de flora vascular de la UE (Cuadro 4) con un total de 5.600 táxones, de los que un $26.6 \%$ corresponden a especies endémicas, valor porcentual más alto del espacio comunitario. Si tomamos estos valores para la Comunidad Valenciana y los comparamos con algunos miembros de la UE, se advierte que el número de endemismos es superior a más de la mitad de estos países, aspecto que se incrementa si tenemos en cuenta su menor superficie territorial.

La trasposición a la legislación española es por $R D$ 1997/1995 modificado por el $R D$ para garantizar la conservación de la biodiversidad (1993/1998) en el que se recogen una serie de medidas para mantener o restablecer determinadas zonas que se encuentran en peligro de desaparecer y que, por sus características medioambientales, merecen la categoría de LICs y ZECs; de este modo, se engrosa la lista de espacios propuestos para la constitución de la Red Natura 2000. Dentro de estas medidas, destaca el requerimiento de un estudio de evaluación de impacto ambiental para cualquier plan, proyecto o actuación que se lleve a cabo dentro de estas áreas.

La propuesta de LICs para la C.V. presentada en abril del año 2000 consta de un total de 39 espacios, que se pueden agrupar en cuatro medios: sectores de montaña, zonas húmedas, riberas de ríos y áreas litorales. Del total de la superficie propuesta (396.588 ha) el mayor valor corresponde a la provincia de Castellón (41.7\%), que, además, será la que tenga un mayor porcentaje de área protegida cuando sean aprobados los LICs. (Cuadro 6).

Desde 1985, el Consejo Comunitario puso en marcha el Programa Corine con el objetivo de recoger información sobre el estado del medioambiente en la UE. Una de las líneas de este programa es el Proyecto Biotopos/Corine, en el que se recopilan todos los espacios

2 La Red Natura 2000 es un proyecto que finaliza en el año 2004 y que consiste en la creación de una red europea de espacios protegidos en la que queden representados los diferentes ecosistemas y especies vegetales y animales más representativos de las regiones biogeográficas de la UE. 
Cuadro 2

LUGARES DE INTERÉS COMUNITARIO (LICS) SOLICITADOS POR LOS PAÍSES DE LA U.E.

\begin{tabular}{|l|r|r|r|}
\hline & $\mathbf{N}^{\mathbf{0}}$ de lugares & Superficie $\left.\mathbf{( k m}^{2}\right)$ & $\begin{array}{c}\text { \% de territorio } \\
\text { nacional }\end{array}$ \\
\hline Luxemburgo & 38 & 352 & 13,6 \\
Portugal & 65 & 12.150 & 13,2 \\
Holanda & 76 & 7.078 & 17,0 \\
Bélgica & 102 & 913 & 3,0 \\
Austria & 113 & 9.450 & 11,3 \\
Dinamarca & 194 & 10.259 & 23,8 \\
Grecia & 234 & 26.522 & 20,1 \\
Irlanda & 259 & 3.007 & 4,3 \\
Gran Bretaña & 340 & 17.660 & $\mathbf{1 7 , 3}$ \\
España & $\mathbf{8 6 7}$ & $\mathbf{8 8 . 0 7 6}$ & 5,7 \\
Francia & 1.029 & 31.440 & 3,0 \\
Alemania & 1.126 & 10.956 & 13,9 \\
Finlandia & 1.381 & 47.154 & 11,3 \\
Suecia & 1.919 & 46.300 & 16,4 \\
Italia & 2.507 & 49.364 & \\
\hline Total & 10.250 & 360.681 & \\
\hline
\end{tabular}

Fuente: SANZ HERRÁIZ, C. y MOLINA HOLGADO, P. (2001): «Espacios naturales protegidos y conservación del medio» en GIL OLCINA, A. y GÓMEZ MENDOZA, J. (coord.): Geografía de España. Ariel Geografía, Barcelona, pág. 218.

de interés comunitario para su conservación. En los últimos años, todas las actuaciones llevadas a cabo se están incorporando a la Red Europea de Medio Ambiente, cuya finalidad más destacada es la de proporcionar e intercambiar información sobre las diferentes líneas desarrolladas para mejorar la protección del medio. En España se han puesto en marcha varios proyectos de esta índole, como son:

- el Programa de Biodiversidad para la Península Ibérica, que consiste en la elaboración de tres publicaciones: Flora Ibérica, Flora Micológica Ibérica y Fauna Ibérica;

- el Banco de Datos de la Naturaleza ${ }^{3}$, que incluye, a su vez, entre otros, el Proyecto Hispanat, que consiste en un inventario de hábitats y espacios naturales que representan la biodiversidad de España, en el que se incluyen todas las redes de estas características como Ramsar o Biotopos/Corine; toda esta información va acompañada de una cartografía automatizada que será el futuro Sistema de Información Geográfica Biotopos.

3 En el Banco de Datos de la Naturaleza se incluyen también un Inventario Forestal Nacional y Mapa Forestal de España a escalas 1:200.000 y 1:50.000, Inventario de especies de Flora y Fauna, acompañado de un atlas de distribución de especies; y un Banco de Datos de la Oficina de Anillamiento. 
Cuadro 3

DIVERSIDAD BIOLÓGICA DE HÁBITATS DE LA DIRECTIVA 92/43 EN ESPAÑA

\begin{tabular}{|l|c|}
\hline Hábitats costeros y halófilos & 140 \\
Dunas litorales y continentales & 21 \\
Hábitats de agua dulce & 77 \\
Brezales & 48 \\
Matorrales & 205 \\
Prados naturales y seminaturales & 208 \\
Turberas & 20 \\
Hábitats rocosos y cuevas & 230 \\
Bosques & 260 \\
Otros & 16 \\
\hline
\end{tabular}

Fuente: Ministerio de Medio Ambiente (2000): Estrategia Española para la conservación y el uso sostenible de la diversidad biológica, pág. 24.

Cuadro 4

DATOS COMPARATIVOS SOBRE FLORA VASCULAR DE DISTINTOS PAÍSES DE LA U.E.

\begin{tabular}{|l|r|c|c|c|}
\hline Territorio & Área $\left(\mathbf{k m}^{2}\right)$ & $\mathbf{N}^{\mathbf{0}}$ táxones & $\mathbf{N}^{\mathbf{0}}$ endemismos* & $\mathbf{\%}$ \\
\hline España & $\mathbf{5 1 7 . 1 3 8}$ & $\mathbf{5 . 6 0 0}$ & $\mathbf{1 . 4 9 1}$ & $\mathbf{2 6 , 6}$ \\
Grecia & 140.317 & 4.992 & 742 & 14,9 \\
Italia & 301.245 & 5.598 & 712 & 12,7 \\
Portugal & 91.631 & 2.573 & 150 & 5,8 \\
Francia & 558.342 & 4.630 & 133 & 2,9 \\
Comunidad Valenciana & $\mathbf{2 3 . 2 5 9}$ & $\mathbf{3 . 0 4 8}$ & $\mathbf{5 9}$ & $\mathbf{1 , 9}$ \\
Austria & 83.853 & 3.028 & 35 & 1,2 \\
Gran Bretaña & 244.754 & 1.623 & 16 & 1,0 \\
Alemania & 552.000 & 3.500 & 6 & 0,2 \\
Bélgica & 30.519 & 1.452 & 1 & 0,1 \\
Dinamarca & 43.075 & 1.252 & 1 & 0,1 \\
Suecia & 449.790 & 1.716 & 1 & 0,1 \\
Holanda & 41.160 & 1.221 & 0 & 0,0 \\
\hline
\end{tabular}

* se consideran sólo los endemismos exclusivos de cada zona.

Fuente: CRESPO VILLALBA, M.B. (2000): «Diversidad vegetal de la Comunidad valenciana: flora vascular de interés», Cuadernos de Biodiversidad, Universidad de Alicante.

\subsubsection{Espacios Naturales Protegidos}

La primera ley promulgada en España sobre Espacios Naturales Protegidos es la de Parques Nacionales en 1916 y su correspondiente $R D$ de 1926, ambos con un criterio estético. A partir de esta fecha y con unos valores similares, se siguen emitiendo leyes pero de carácter sectorial (BOX y MARCO, 1991: 181-182). No es hasta 1975, con la Ley de 


$$
\text { Cuadro } 5
$$

CLASIFICACIÓN DE LOS ENDEMISMOS VEGETALES EN LA COMUNIDAD VALENCIANA SEGÚN LAS CATEGORÍAS DE LA UICN

\begin{tabular}{|c|c|c|c|c|c|c|c|c|}
\hline & \multirow{2}{*}{$\begin{array}{c}\begin{array}{c}\text { Especies } \\
\text { extintas }\end{array} \\
\text { EW }\end{array}$} & \multicolumn{3}{|c|}{ Especies amenazadas } & \multicolumn{2}{|c|}{$\begin{array}{l}\text { Especies con } \\
\text { menor riesgo }\end{array}$} & \multirow[b]{2}{*}{ total } & \multirow[b]{2}{*}{$(\%)^{*}$} \\
\hline & & CR & EN & VU & LRnt & LRIc & & \\
\hline Endemismos de la C. Valenciana & & 2 & 5 & 20 & 12 & 20 & 59 & 16,9 \\
\hline Endemismos C.V. y zonas limítrofes & & 6 & 1 & 17 & 14 & 33 & 71 & 20,3 \\
\hline $\begin{array}{l}\text { Endemismos ibéricos de amplia } \\
\text { distribución }\end{array}$ & 1 & 4 & 4 & 37 & 46 & 128 & 220 & 62,8 \\
\hline Porcentaje & 0,29 & 3,43 & 2,86 & 21,14 & 20,57 & 51,71 & & \\
\hline
\end{tabular}

*Porcentaje respecto del total de plantas endémicas.

Leyenda: EW, endemismo extinto en estado silvestre; CR, amenazado en peligro crítico; EN, en peligro; VU, vulnerable; LRnt, de riesgo menor casi amenazada; LRlc, riesgo menor de preocupación menor.

Fuente: CRESPO VILLALBA, M.B. (2000): «Diversidad vegetal de la Comunidad Valenciana: flora vascular de interés», Cuadernos de Biodiversidad, Universidad de Alicante.

Espacios Naturales Protegidos, cuando aparece un nuevo concepto: la protección de especies en peligro de extinción.

El mayor avance en normativa proteccionista se da con la ley 4/1989 de 27 de marzo de Conservación de los Espacios Naturales y de la Flora y Fauna silvestres que sustituye a la anterior porque no se adaptaba a la nueva España de las autonomías. En ella se establece la creación del Catálogo Nacional de Especies Amenazadas con cuatro categorías distintas: en peligro de extinción, sensibles a la alteración del hábitat, vulnerables y de interés especial; finalmente, sólo se consideraron la primera y última. Las figuras creadas para la protección de Espacios Naturales son: Parques Nacionales (responsabilidad de la Administración Central), Reservas Naturales, Monumentos Naturales y Paisajes Protegidos. La novedad es la creación de los Planes de Ordenación de los Recursos Naturales y de las Directrices para la Ordenación de los Recursos Naturales. Estos Planes ponen límite a otros instrumentos de ordenación territorial o física, prevaleciendo sobre ellos (Título II, pág. 4), y se exige la aplicación del régimen de evaluación establecido en el RD 1302-1986 de EIA para todas las actividades, obras o instalaciones públicas o privadas que se vayan a efectuar dentro de estos espacios. En estos Planes y Directrices se recogen también la delimitación del ámbito territorial, características del medio físico y biológico, estado de conservación, formulación de un diagnóstico y previsión de evolución futura, y determinación de las limitaciones de usos y aprovechamientos. En el caso de Espacios Naturales, todavía no declarados pero con una clara amenaza, se establece un Régimen de Protección Preventiva. Para el caso concreto de las zonas húmedas se determina la realización de un Inventario Nacional de Zonas Húmedas, para conocer su evolución e indicar las medidas de protección que deben recogerse en los planes hidrológicos de cuencas.

Uno de los objetivos de esta ley es la creación de la Red de Parques Nacionales, regulada por la figura del Plan Director que se aprueba por el RD 1803/1999 de 26 de noviembre y que es un instrumento de gestión y de planificación de estos espacios. El desequilibrio interregional de esta red se pone de manifiesto en el informe Estrategia 
Cuadro 6

PROPUESTA DE LICS PARA LA COMUNIDAD VALENCIANA (ABRIL 2000)

\begin{tabular}{|c|c|c|c|c|}
\hline Provincia & LICs & $\begin{array}{c}\text { Superficie } \\
\text { (ha) }\end{array}$ & $\begin{array}{c}\text { Total } \\
\text { superficie } \\
\text { (ha) y \% }\end{array}$ & $\begin{array}{c}\text { Sup. } \\
\text { provincial } \\
\text { protegida } \%\end{array}$ \\
\hline ALICANTE & $\begin{array}{l}\text { El Fondo } \\
\text { Les Llacunes de la Mata y Torrevieja } \\
\text { Les salines de Santa Pola } \\
\text { Marjal de Pego-Oliva } \\
\text { El Montgó } \\
\text { Peñón de Ifach } \\
\text { Serra de Mariola y el Carrascar de la Font Roja } \\
\text { Penya-Segats del Nord d'Alacant } \\
\text { Serres d'Aitana, Serrella, de la Xorta y el Puigcampana } \\
\text { Serres de Bèrnia y del Ferrer } \\
\text { Serra Gelada i Illa de Benidorm } \\
\text { Serra de Crevillent } \\
\text { Serra de Callosa } \\
\text { L'Illa de Tabarca y l'entorn marí } \\
\text { Les Dunes de Guardamar } \\
\text { Sierra de Orihuela }\end{array}$ & $\begin{array}{l}2.495 \\
3.707 \\
2.574 \\
1.252 \\
2.475 \\
48 \\
19.757 \\
1.741 \\
17.312 \\
3.582 \\
908 \\
5.105 \\
686 \\
14.460 \\
865 \\
2.340\end{array}$ & $\begin{array}{l}79.307 \\
19,9 \%\end{array}$ & 13,6 \\
\hline CASTELLÓN & $\begin{array}{l}\text { La Tinençà de Benifassà i les serres del Turmell i la } \\
\text { Valliviana } \\
\text { L'Alt Maestrat } \\
\text { Penyagolosa } \\
\text { Alto Palancia } \\
\text { La Marjal d'Almenara } \\
\text { Riu Bergantes } \\
\text { El Desert de les Palmes } \\
\text { Illes Columbretes } \\
\text { Prat de Cabanes-Torreblanca } \\
\text { Serra d'Espadà }\end{array}$ & $\begin{array}{c}34.000 \\
25.132 \\
28.310 \\
26.343 \\
1.544 \\
2.818 \\
3.293 \\
12.300 \\
917 \\
31.023\end{array}$ & $\begin{array}{c}165.680 \\
41,7 \%\end{array}$ & 24,7 \\
\hline VALENCIA & $\begin{array}{l}\text { Serra de la Calderona } \\
\text { Puebla de San Miguel } \\
\text { El Sabinar de Alpuente } \\
\text { Sierras de Utiel, Negrete, Ropé y el Tejo } \\
\text { Las Hoces del Cabriel } \\
\text { Sierras Martés, del Ave y del Caballón } \\
\text { Valle de Ayora y Sierra del Boquerón } \\
\text { Serra de Corbera } \\
\text { Serres de Mondúver y la Marjuquera } \\
\text { El Alto Turia } \\
\text { Rius d'Ademus } \\
\text { L'Albufera } \\
\text { Marjal dels Moros }\end{array}$ & $\begin{array}{c}17.769 \\
8.861 \\
5.765 \\
18.579 \\
5.535 \\
38.269 \\
17.441 \\
4.986 \\
7.363 \\
3.802 \\
2.061 \\
20.932 \\
238\end{array}$ & $\begin{array}{c}151.601 \\
38,2 \%\end{array}$ & 14,07 \\
\hline
\end{tabular}

Fuente: Ministerio de Medio Ambiente. Elaboración propia. 
Española para la conservación y el uso sostenible de la diversidad biológica, así como la total escasez de otras figuras de protección, si tenemos en cuenta la gran biodiversidad del país. La situación resulta contradictoria: por un lado, hay una proliferación de espacios protegidos que, en muchas ocasiones, responden a un interés propagandístico, de atracción de fondos económicos para dinamizar una zona o en un intento de planificar y ordenar racionalmente un territorio que está siendo explotado turísticamente y en el que es necesaria la protección de su paisaje, flora y fauna; por otro, la no inclusión de algunas áreas que son merecedoras de esta catalogación, debido al excesivo peso que tiene el elemento botánico en las declaraciones (TROITIÑO, 1995).

En la C.V., no se empieza a desarrollar una política proteccionista hasta la aprobación del Estatuto de Autonomía en 1982; a excepción de la Albufera de Valencia. Desde esta fecha y hasta la ley 11/1994 de 27 de diciembre de Espacios Naturales Protegidos de la Generalitat Valenciana, se declaran cinco Parques Naturales (Peñón de Ifach, Montgó, Carrascal de la Font Roja en Alicante; Illes Columbretes en Castellón y L'Albufera de Valencia) a través de la Ley de Espacios Naturales de 1975, y cinco Parajes Naturales (El Fondó, Salines de Santa Pola y Lagunas de Torrevieja-La Mata en Alicante; Desert de les Palmes y Prat de Cabanes-Torreblanca en Castellón) con la ley 5/1988 de 24 de junio reguladora de los Parajes Naturales de la Generalitat Valenciana.

La nueva ley de 1994 sustituye a las dos anteriores y establece nuevas figuras de protección para el territorio autonómico valenciano: Parque Natural, Paraje Natural, Paraje Natural Municipal ${ }^{4}$, Reserva Natural, Monumento Natural, Sitio de Interés y Paisaje Protegido, además de una protección general para zonas húmedas, cuevas y vías pecuarias. Los instrumentos de ordenación son: los Planes de Ordenación de Recursos Naturales, que superan el espacio protegido y se aplican a Parques Naturales y Reservas Naturales; Planes Rectores de Uso y Gestión, para las mismas figuras que el anterior, además de Parajes Naturales y Paisajes Protegidos; Planes Especiales, que regulan a los Parajes Naturales Municipales; y Normas de Protección para los Monumentos Naturales y Sitios de Interés. En el caso concreto de las Zonas Húmedas, se establece la realización de un catálogo con su delimitación, de modo que el planeamiento urbanístico las tenga en cuenta y adopte especiales precauciones para garantizar su conservación. En general, lo establecido en estos instrumentos prevalece sobre el ordenamiento y la planificación territorial; excepto en los Planes Especiales que se han de ajustar a la legislación urbanística y, además, requieren la estimación del impacto ambiental para su aprobación definitiva. Por otro lado, cada figura puede incluir un área de amortiguación de impactos, cuya protección se llevará a cabo con la regulación de los usos y actividades o se exigirá una EIA o un informe del órgano gestor del espacio protegido. En la actualidad, es la provincia de Alicante la que reúne un mayor número de espacios protegidos, sobre todo como Paraje Natural, fundamentalmente localizados en la franja costera. Por último, señalar que existen solicitudes para la declaración de Parajes Naturales Municipales, aún no aprobados, pero no así de Sitios de Interés y de Paisajes Protegidos (Cuadro 7).

4 La figura legal de Paraje Natural Municipal fue creada con anterioridad a la Ley de Espacios Naturales Protegidos de la Comunidad Valenciana por la Ley de Suelo No Urbanizable 4/92 de 5 de junio. Debido a la escasa claridad en el procedimiento de su declaración, se regula posteriormente por el Decreto 109/1998 de 29 de julio. 
Cuadro 7

ESPACIOS NATURALES PROTEGIDOS EN LA COMUNIDAD VALENCIANA

\begin{tabular}{|c|c|c|c|}
\hline Figura de protección & Número total & & Espacios naturales \\
\hline \multirow[t]{3}{*}{ Parque Natural } & \multirow[t]{3}{*}{6} & Alicante & $\begin{array}{l}\text { Penyal d'Ifac } \\
\text { Montgó } \\
\text { Carrascar de la Font Roja } \\
\text { Marjal de Pego-Oliva }\end{array}$ \\
\hline & & Castellón & Serra d'Espadà \\
\hline & & Valencia & L'Albufera \\
\hline \multirow[t]{2}{*}{ Paraje Natural } & \multirow[t]{2}{*}{5} & Alicante & $\begin{array}{l}\text { El Fondó } \\
\text { Lagunas de Torrevieja-La Mata } \\
\text { Salines de Santa Pola }\end{array}$ \\
\hline & & Castellón & $\begin{array}{l}\text { Desert de Les Palmes } \\
\text { Prat Cabanes-Torreblanca }\end{array}$ \\
\hline \multirow[t]{3}{*}{ Paraje Natural Municipal } & \multirow[t]{3}{*}{$6^{*}$} & Alicante & $\begin{array}{l}\text { Arenal de Petrer } \\
\text { Buenaventura-Canalons } \\
\text { Clot de Galvany }\end{array}$ \\
\hline & & Castellón & Balsa de la Dehesa de Ensoneja \\
\hline & & Valencia & $\begin{array}{l}\text { Clot de la Mare de Deu } \\
\text { Rodanas }\end{array}$ \\
\hline \multirow[t]{2}{*}{ Reserva Natural } & \multirow[t]{2}{*}{3} & Alicante & $\begin{array}{l}\text { Cabo de San Antonio } \\
\text { Isla de Tabarca }\end{array}$ \\
\hline & & Castellón & Illes Columbretes \\
\hline Monumento Natural & $1 *$ & Castellón & Peñas Aragonesas \\
\hline Sitio de Interés & 0 & & \\
\hline Paisaje Protegido & 0 & & \\
\hline
\end{tabular}

* En vías de aprobación

Fuente: Consellería de Medio Ambiente. Generalitat Valenciana. Elaboración propia.

\subsection{Protección a escala de detalle}

\subsubsection{Flora endémica, rara o amenazada}

Estos conceptos surgen a partir de los años noventa del siglo pasado y vienen a referirse a tres calificativos diferentes, pero que pueden darse en una misma especie vegetal. El endemismo se establece como una categoría corológica o de distribución espacial de una determinada planta, la rareza es el opuesto a la abundancia y la amenaza se define por el riesgo a que desaparezca ésta ante una determinada presión o uso. Una especie vegetal puede estar amenazada, aunque no reúna las otras dos categorías, por lo que también merece una protección. El grado de amenaza está establecido por la Unión Internacional para la Conservación de la Naturaleza (UICN) en 1994, en diez categorías que, de mayor a menor gravedad, son las siguientes: extinta, extinta en estado silvestre, amenazada (en peligro crítico, en peligro, vulnerable), riesgo menor (dependiente de conservación, casi amenazada, preocupación menor), datos insuficientes y no evaluada (LAGUNA et alteri, 1998). 
Dentro de la UE, España reúne la mayor biodiversidad debido a su situación biogeográfica limítrofe entre la región eurosiberiana y la mediterránea, reflejado en unos 8.000 táxones que componen su flora, de los que el $60 \%$ corresponden a plantas vasculares (helechos y plantas con flor). Además reúne aproximadamente la mitad de los endemismos europeos, unas 1.500 especies (Cuadro 4), donde las islas Canarias juegan un papel importante, debido a su aislamiento geográfico que le confiere un mayor grado de endemicidad.

Pese a que desde finales del siglo XX existe un aumento de la protección de especies con estas características, es evidente que siguen estando amenazadas en su mayoría. Dentro del territorio nacional hay varias estrategias de conservación de flora, a escala de especie, en Andalucía, Aragón, Canarias y Comunidad Valenciana. En este tipo de actuaciones es importante tener en cuenta que han de existir dos frentes de acción: beneficio a muchas y a pocas especies. Entre las primeras, tendríamos el llevar a cabo un banco de semillas, programas provinciales de protección, etc; y en las segundas, sirvan de ejemplo la reintroducción de especies o planes de recuperación. Los métodos para ejecutarlo también son dos: legislación y aplicación directa de ésta u otras iniciativas, que, en general, se pueden agrupar en cuatro tipos o campos diferentes como son científico (estudios o investigaciones sobre dinámica vegetal), técnico (gestión, supervisión), jurídico (aparato legislativo, figuras de protección) y divulgativo (educación ambiental, campañas de información pública) (LAGUNA et alteri, 1998).

Desde el Servicio de Protección de Especies de la Consellería de Medio Ambiente de la Generalitat Valenciana, existen varios proyectos con financiación europea (proyecto LIFE) cuyo fin es la conservación de estas especies, como: Banco de Germoplasma en el Jardín Botánico de Valencia, cultivos in vitro de especies amenazadas en el Instituto Valenciano de Investigaciones Agrarias, la creación de una Red de Microrreservas de Flora. Todas estas acciones quedan justificadas por la gran biodiversidad y número de endemismos que reúne el territorio valenciano dentro de la Península Ibérica y de la UE (Cuadro 4), sin contar con los de zonas limítrofes a la Comunidad Valenciana e ibéricos de amplia distribución. De los primeros, aproximadamente la mitad están amenazados según la clasificación de la UICN (1994), cifra que resulta menos preocupante si incluimos los segundos, un $27.72 \%$ (Cuadro 5). Contrariamente a lo que se pueda pensar, la mayor parte se localizan en matorrales heliófilos, roquedos o ambientes de orla de formación forestal o arbórea donde las condiciones ambientales son más duras y las plantas alcanzan una elevada especialización. Este hecho es muy importante y ha de ser tenido en cuenta en la ordenación del territorio o en las prácticas forestales, ya que estos medios suelen coincidir con los terrenos menos valorados y más esquilmados cuando, en realidad, reúnen una mayor riqueza de flora rara y endémica, sin olvidar el valor cultural que tienen muchas de estas especies. (Cuadro 1)

\subsubsection{Microrreservas de flora}

La Comunidad Valenciana es el único territorio europeo que tiene una figura de protección parcial y específica de flora, a través de la microrreserva (Decreto 218/1994 del 17 de octubre, DOGV 3/11/94). La legislación actual oscila entre la protección de un espacio máximo y la especie en sí misma; con esta medida se cubre la escala intermedia, puesto que se define como parcela inferior a las veinte hectáreas en terreno público o privado, que reúna especies vegetales raras, endémicas o amenazadas que requieran su protección. La novedad es doble: 
- la conservación deja de ser un fin para convertirse en un medio, puesto que la finalidad es científica, con lo que se pretenden crear pequeños laboratorios naturales, un banco de germoplasma, fomentar la educación ambiental y desarrollar una red valenciana de microrreservas que sea representativa de la biodiversidad de la Comunidad Valenciana;

- y el procedimiento legal se agiliza ya que el plan de gestión científico-técnico se aprueba al tiempo que esta figura (PADILLA y RAMÓN, 1997).

Este proyecto nace ya en 1991 dentro del programa $\mathrm{MAB}^{5}$ de UNESCO. En la actualidad, está siendo cofinanciado al $50 \%$ por la UE a través del Programa LIFE y está adscrito a varias redes internacionales de intercambio científico y técnico, como el ya mencionado programa MAB-UNESCO, dentro de acciones de la Plataforma Europea o la red Eurosite, entre otros. La red, hoy en día, consta de un total de 125 microrreservas para toda la Comunidad Valenciana, de las cuales 51 están en Alicante, 22 en Castellón y 52 en Valencia. No hace falta remarcar el desequilibrio territorial.

El Servicio de Protección de Especies de la Consellería de Medio Ambiente de la Generalitat Valenciana está desarrollando toda una serie de actividades al amparo de esta red como son: herbarios, estudios corológicos y taxonómicos, censos y estudios de dinámica poblacional, estudios genéticos y de biología floral, programas de conservación a media escala, conservación a través de bancos de semillas, viveros, técnicas in vitro, recolección y conservación de material genético, revegetación con siembras o plantaciones de las especies amenazadas, actuaciones educativas y formativas. Dentro de las futuras actividades que pretende desarrollar, destacan la elaboración y aprobación del Catálogo Valenciano de Flora Amenazada, con actualización legal de la normativa existente sobre la conservación de flora, árboles monumentales o singulares y de la flora agraria en extinción; y la firma de convenios de colaboración entre la Consellería de Medio Ambiente, Universidades, centros de investigación y ONGs (LAGUNA et alteri, 1998).

Algunos de los problemas que presentan estas microrreservas en la actualidad, pero que son merecedores de un estudio más exhaustivo, son, fundamentalmente, los relacionados con la tensión territorial ante otros usos, sobre todo los urbanísticos, y, aún más, los relacionados con el turismo; y la declaración de zonas de protección en propiedad privada. El primero deriva en una ocupación total o parcial de las microrreservas por estas actividades que,a su vez, pone de manifiesto la falta de control y vigilancia por parte de la Generalitat Valenciana. En la Orden de 7 de diciembre de 1995 por la que se regula la señalización de las microrreservas de flora (DOGV, 2/1/96), ya se hace referencia: «Hay una evidente necesidad legal de señalizar los perímetros, dado que existen limitaciones de uso e infracciones que sólo se dan dentro de la microrreserva y no fuera de ésta; en consecuencia la Adminis-

5 Merece destacar dentro del Programa del Hombre y la Biosfera (MAB) de la UNESCO, la declaración de dieciséis Reservas de la Biosfera en España (por orden cronológico de declaración): Grazalema (Cádiz), OrdesaViñamala (Huesca), Montseny (Barcelona-Girona), Doñana (Huelva-Sevilla), Mancha Húmeda (Ciudad Real), El Canal y los Tiles (La Palma-Sta. Cruz de Tenerife), Sierras de Cazorla y Segura y las Villas (Jaén), Marismas de Odiel (Huelva), Urdarbai (Vizcaya), Sierra Nevada (Granada), Cuenca Alta del Manzanares (Madrid), Isla de Lanzarote (Lanzarote-Las Palmas), Isla de Menorca (Islas Baleares), Sierras de las Nieves y su entorno (Málaga), Cabo de Gata (Almería) y El Hierro (El Hierro-Sta. Curz de Tenerife). Si bien, en un principio, fueron concebidas con unos objetivos similares a las ZECs europeas, en algunos casos se han convertido en un reclamo turístico o en un medio de obtención de ayudas económicas, al tiempo que se siguen esquilmando estos espacios. Uno de los ejemplos más claros es el de la Mancha Húmeda (SANZ y MOLINA, 2001). 
tración tiene la obligación de indicar con suficiente precisión a los ciudadanos si se encuentran dentro o fuera de los perímetros de protección». El segundo problema mencionado se soluciona con la declaración en terreno público de un área de similares características y flora, lo que, en ocasiones, y sobre todo en zonas de litoral, puede desembocar a la situación anterior.

Si observamos la red actual de microrreservas de flora en el territorio valenciano, a parte del desequilibrio manifiesto entre la provincia de Castellón y las de Valencia y Alicante, es evidente que la mayoría de estas áreas se localizan en zonas del interior, inaccesibles y, sobre todo, lejos de cualquier especulación del suelo; mientras que el sector litoral, más problemático a la hora de la declaración, pero con una flora más amenazada, se trata de soslayo.

\subsubsection{Catálogos florísticos}

A escala nacional el primer Catálogo Florístico se inicia con el $R D$ 3891/1982 y la Orden de septiembre de 1984, en la actualidad derogados, en el que sólo se incluían dos plantas valencianas: Cardancellus dianus y Silene hifacensis; aunque se preveía que las CCAA publicaran listas complementarias en sus respectivos territorios, estableciendo los niveles de protección que consideraran oportunos. El Catálogo Nacional de Especies Amenazadas queda regulado por RD 439/1990 de 30 de marzo según lo establecido en la Ley 41989 de Conservación de Espacios Naturales y de Flora y Fauna Silvestres, en la que se prevé la catalogación de especie, subespecie o población amenazada, realizada por el ICONA y elevado a la Comisión Nacional de la Naturaleza, actual Comité de Fauna y Flora del Ministerio de Medio Ambiente. Las categorías contempladas, teniendo como referencia las de la UICN, son: peligro de extinción, vulnerable, sensible a la alteración del hábitat y de interés especial. Este catálogo ha sido ampliado posteriormente por dos Órdenes en 1996 y 1998. Las especies vegetales valencianas recogidas en él, se catalogan dentro de la primera y última categoría (Cuadro 8). Algunas de éstas son citadas en la Directiva de Hábitats de 1992, en el anexo II, referido a la conservación a través de la declaración de ZECs, en el IV, que requiere una estricta protección, y en el V, referido a una explotación gestionada (Cuadro 9).

En mayo de 2001, el Ministerio de Medio Ambiente publica la Lista Roja de Flora vascular amenazada en la que se establecen prioridades de conservación siguiendo las catego-

Cuadro 8

ESPECIES VEGETALES VALENCIANAS RECOGIDAS EN EL CATÁLOGO NACIONAL DE ESPECIES AMENAZADAS

\begin{tabular}{|l|l|}
\hline En peligro de extinción & $\begin{array}{l}\text { Cistus heterophyllus ssp carthaginesis (Pau) M.B. Crespo } \\
\text { \& G. Mateo }\end{array}$ \\
& Lepidium cardamines L \\
& Limonium cavanillesii Erben \\
& Medicago citrina (Font Quer) Greuter \\
\hline De interés especial & Carduncellus dianus Webb. \\
& Silene hifacensis Rouy ex Willk \\
\hline
\end{tabular}

Fuente: CRESPO VILLALBA, M.B. (2000): «Diversidad vegetal de la Comunidad Valenciana: flora vascular de interés», Cuadernos de Biodiversidad, Universidad de Alicante. 
Cuadro 9

ESPECIES VEGETALES VALENCIANAS RECOGIDAS EN LA DIRECTIVA DE HÁBITATS

\begin{tabular}{|l|l|}
\hline Anexo II & Diplotaxis ibicensis (Pau) Gómez-Campo \\
& Helianthemum caput-felis Boiss \\
& Kosteletzkya pentacarpos (L) Ledeb \\
& Marsilea batardae Launert. \\
& M. quadrifolia L. \\
& M. strigosaWilld. \\
& Sideritis glauca Cav. \\
& Teucrium lepicephalum Pau \\
& Presencia improbable en C.Valenciana: \\
& Lythrum flexuosum Lag. \\
& Sisymbrium cavanillesianum Castroviejo \& Valdés \\
& Berm. \\
\hline Anexo IV & Euphorbia nevadensis Boiss. \& Rent ssp \\
& nevadensis \\
& Spiranthes aestivalis (L) Koch \\
\hline Anexo V & Ruscus aculeatus \\
\hline
\end{tabular}

Fuente: CRESPO VILLALBA, M.B. (2000): «Diversidad vegetal de la Comunidad Valenciana: flora vascular de interés», Cuadernos de Biodiversidad, Universidad de Alicante.

rías de la UICN (1994). La representación de especies de la Comunidad Valenciana es la más importante en la actualidad y completa la de otros catálogos florísticos realizados con el mismo fin (Cuadro 10).

En el ámbito autonómico valenciano, se modificó el $R D$ 3891/1982 por la Orden de 20 de diciembre de 1985 de la Consellería de Agricultura y Pesca, en la que se establecieron sólo tres niveles de protección, para evitar una jerarquía demasiado extensa y confusa: estrictamente protegidas, donde sólo se admite su recogida o corta con fines científicos, educativos o conservacionistas; una situación intermedia en la que se requiere la previa autorización de la Consellería de Medio Ambiente para su manejo; y un tercer grado, en el que sólo se autoriza la toma de partes o semillas de las plantas, quedando prohibido para fines comerciales (Cuadro 11). De los tres niveles de protección, sólo el primero recoge un mayor número de especies vegetales endémicas (no sólo de la Comunidad Valenciana, sino también ibéricas), de las cuales menos de la mitad, unas siete, se pueden considerar como amenazadas si aplicamos las categorías de la UICN (1994). Hay que tener en cuenta que este $R D$ no está emitido por la Consellería de Medio Ambiente, por lo que los fines de conservación están dirigidos a la protección de flora que pueda ser utilizada con fines comerciales.

Desde el Servicio de Protección de Especies de la Consellería de Medio Ambiente, se realizó hace unos años una propuesta de lista roja de flora vascular (LAGUNA et alteri, 1998), anterior a la de ámbito nacional, en la que se agruparon las especies amenazadas según las categorías de la UICN (1994). Del total de táxones, 225, el 5.3\% corresponde a especies extintas en estado silvestre (EW) y, sobre todo, destaca el $16.4 \%$ de las que se encuentran en peligro crítico (CR), algunas de ellas recogidas en la lista roja nacional; aunque el mayor número pertenece a la categoría de vulnerable (VU) (Cuadro 12). Esta propuesta completa los listados y catálogos florísticos vigentes en la actualidad ya que, en realidad, se trata de un preámbulo del futuro Catálogo Valenciano de Especies Amenazadas, 
Cuadro 10

ESPECIES VEGETALES VALENCIANAS EN LA LISTA ROJA DE FLORA VASCULAR AMENAZADA. MAYO 2001

\begin{tabular}{|c|c|c|c|}
\hline Táxones & $\begin{array}{l}\text { Nivel de } \\
\text { Protección }\end{array}$ & Táxones & $\begin{array}{l}\text { Nivel de } \\
\text { protección }\end{array}$ \\
\hline Lemnáceas & & Thymus webbianus Rouy & $\mathrm{EN}: \mathrm{B} 1+2 \mathrm{c}$ \\
\hline Lemna trisulca $\mathrm{L}$ & $\mathrm{C} 1$ & Thymus moroderi Pau ex Martínez & VU: A2c, D2 \\
\hline UMBELÍFERA & & CISTÁCEAS & \\
\hline $\begin{array}{l}\text { Carum foetidum (Coss. \& Durieu) } \\
\text { Benth \& Hook. f. }\end{array}$ & DD & $\begin{array}{l}\text { Cistus heterophyllus subsp } \\
\text { carthaginensis (Pau) M.B. Crespo \& } \\
\text { G. Mateo }\end{array}$ & CR: A2e, B1+2e, \\
\hline $\begin{array}{l}\text { Hohenackeria exscapa (Steven) Kos.- } \\
\text { Pol. }\end{array}$ & DD & Helianthemum caput-felis Boiss. & VU: A2c, D2 \\
\hline PALMÁCEA & & $\begin{array}{l}\text { Helianthemum marminorense Alcaraz } \\
\& \text { al. }\end{array}$ & DD \\
\hline Phoenix canariensis Chabaud & VU: $\mathrm{B}+2 \mathrm{c}$ & MALVÁCEAS & \\
\hline AMARILIDÁCEAS & & $\begin{array}{l}\text { Lavatera mauritanica subsp. davaei } \\
\text { (Cout.) Cout. }\end{array}$ & VU: D2 \\
\hline Leucojum valentinum $\mathrm{Pau}$ & VU: A2c, D2 & MARSILEÁCEAS & \\
\hline COMPUESTAS & & Marsilea batardae Launert., & CR: Alace \\
\hline $\begin{array}{l}\text { Centaurea podospermifolia Loscos \& } \\
\text { J. Pardo }\end{array}$ & VU: D2 & Marsilea quadrifolia $\mathrm{L}$. & CR:A1a, 1+2abc \\
\hline Centaurea saxicola Lag. & VU: D2 & COMELINÁCEAS & \\
\hline Filago desertorum Pomel & DD & Cymodocea nodosa (Ucria) Asch. & DD \\
\hline CAMPÁNULAS & & ZANIQUELIÁCEAS & \\
\hline $\begin{array}{l}\text { Wahlembergia nutabunda (Guss.) A. } \\
\text { DC. }\end{array}$ & VU: B1+2c+3d, D2 & $\begin{array}{l}\text { Zannichellia contorta (Desf.) } \\
\text { Chamisso \& Schelch. }\end{array}$ & VU: D2 \\
\hline CRUCÍFERA & & CIPERÁCEAS & \\
\hline $\begin{array}{l}\text { Biscutella stenophylla ssp leptophylla } \\
\text { (Pau) Mateo \& M.B. Crespo }\end{array}$ & DD & Scirpus pungens Vahl & EN: B1+2bcd \\
\hline $\begin{array}{l}\text { Kernera saxatilis (L.) Rchb.ssp } \\
\text { boissirei (Reut. Ex boiss. \& Reut.) } \\
\text { Nyman }\end{array}$ & VU: B1+2c, D2 & PAPAVERÁCEAS & \\
\hline $\begin{array}{l}\text { Sysimbrium cavanillesianum } \\
\text { Castroviejo \& Valdés Berm. }\end{array}$ & VU: B2bcd+3d & Fumaria munbyi Boiss. \& Reut. & VU: D2 \\
\hline Vella lucentina M.B. Crespo & VU: A2c, D2 & PLUMBAGINÁCEAS & \\
\hline RESEDÁCEAS & & Limonium dufourii (Girard) Kuntze, & CR: A2ce \\
\hline Reseda hookeri Guss. & $\mathrm{EN}: \mathrm{B} 1+2 \mathrm{bc}$ & $\begin{array}{l}\text { Limonium mansanetianum M.B. } \\
\text { Crespo \& M.D. Lledó }\end{array}$ & VU:A2c,C2a, D2 \\
\hline CARIOFILÁCEAS & & Limonium parvibracteatum Pignatti & VU: $A 1 c+2 c$ \\
\hline $\begin{array}{l}\text { Arenaria aggregata subsp. } \\
\text { pseudoarmeriastrum (Rouy) G. López } \\
\& \text { Nieto Fel. }\end{array}$ & DD & Limonium lobetanicum Erben & DD \\
\hline Petrocoptis pardoi $\mathrm{Pau}$ & VU: B1+2c, C2a & Limonium cofrentanum Erben & VU: D2 \\
\hline Silene diclinis (Lag.) M. Laínz & $\mathrm{EN}: \mathrm{C} 1+2^{\mathrm{a}}$ & Limonium sucronicum Erben & $\mathrm{DD}$ \\
\hline Silene hifacensis Rouy ex Willk. & VU: C2a, D2 & $\begin{array}{l}\text { Limonium scopulorum M.B. Crespo \& } \\
\text { M.D. Lledó }\end{array}$ & VU: A1c, D2 \\
\hline
\end{tabular}




\begin{tabular}{|c|c|c|c|}
\hline NICTAGINÁCEAS & & Limonium santapolense Erben & VU:A1ce+2c, D2 \\
\hline Boerhavia repens $\mathrm{L}$. & $\mathrm{CR}: \mathrm{B} 1+2 \mathrm{c}$ & $\begin{array}{l}\text { Limonium densissimum (Pignatti) } \\
\text { Pignatti, }\end{array}$ & VU: A1e, B1+2c \\
\hline $\begin{array}{l}\text { Commicarpus africanus (Lour.) } \\
\text { Dandy }\end{array}$ & VU: C2a, D2 & $\begin{array}{l}\text { Limonium rigualii M.B. Crespo \& } \\
\text { Erben }\end{array}$ & VU: A1c, D2 \\
\hline CUPRESÁCEAS & & Limonium thiniense Erben & VU: D2 \\
\hline $\begin{array}{l}\text { Juniperus oxycedrus subsp. } \\
\text { macrocarpa }(\mathrm{Sm} .) \text { Ball }\end{array}$ & CR: B1+2c & GRAMÍNEAS & \\
\hline Tetraclinis articulata (Vahl) Masters & VU: A1a, D2 & Ammochloa palaestina Boiss. & VU: B1+2c, D2 \\
\hline VALERIANÁCEAS & & $\begin{array}{l}\text { Puccinellia fasciculata (Torrey) E.P. } \\
\text { Bicknell }\end{array}$ & $\mathrm{DD}$ \\
\hline Valerianella martinii Loscos & $\mathrm{DD}$ & RANUNCULÁCEAS & \\
\hline EUFORBIÁCEAS & & Thalictrum maritimum Léon Dufour, & VU: A1c+2c \\
\hline Chamaesyce peplis (L.) Prokh. & $\mathrm{DD}$ & ROSÁCEAS & \\
\hline LEGUMINOSAS & & Sanguisorba ancistroides (Desf.) Ces. & $\mathrm{DD}$ \\
\hline $\begin{array}{l}\text { Argyrolobium uniflorum (Decne) Jaub. } \\
\& \text { Spach }\end{array}$ & VU: D2 & SALICÁCEAS & \\
\hline Astragalus danicus Retz. & DD & Salix tarraconensis Pau & VU: C2a, D2 \\
\hline Medicago citrina (Font Quer) Greuter & EN: B1+2e & LENTIBULARIÁCEAS & \\
\hline ASCLEPIADÁCEAS & & $\begin{array}{l}\text { Pinguicula dertosensis (Cañigueral) } \\
\text { G. Mateo \& M.B. Crespo }\end{array}$ & VU: D2 \\
\hline $\begin{array}{l}\text { Caralluma munbyana subsp. } \\
\text { hispanica (Coincy) M.B. Crespo \& G. } \\
\text { Mateo }\end{array}$ & VU: D2 & PLANTAGINÁCEAS & \\
\hline RUBIÁCEAS & & Plantago notata Lag. & $\mathrm{DD}$ \\
\hline $\begin{array}{l}\text { Asperula paui subsp. dianensis (Font } \\
\text { Quer) Romo }\end{array}$ & VU: B1+2c, C2a & ESCROFULARIÁCEAS & \\
\hline GERIANÁCEAS & & Anarrhinum fruticosum Desf & $\mathrm{CR}: \mathrm{B} 1+2 \mathrm{~b}, \mathrm{C} 2 \mathrm{~b}$ \\
\hline Erodium aguilellae López Udias \& al. & DD & $\begin{array}{l}\text { Antirrhinum valentinum Font Quer } \\
\text { subsp. valentinum }\end{array}$ & VU: A2c, B1+2c, \\
\hline LABIADAS & & Antirrhinum pertegasii Rothm. & VU: C2a, D2 \\
\hline Sideritis glauca Cav. & VU: D2 & Linaria orbensis Carretero \& Boira & EN: A2ce, B1+2c \\
\hline Teucrium campanulatum $\mathrm{L}$. & VU: D2 & $\begin{array}{l}\text { Linaria depauperata subsp. } \\
\text { hegelmaieri (Lange) De la Torre \& al. }\end{array}$ & VU: B1+3d, D2 \\
\hline Teucrium lepicephalum $\mathrm{Pau}$ & VU: B1+2c, D2 & $\begin{array}{l}\text { Verbascum fontqueri Benedí \& J.M. } \\
\text { Monts. }\end{array}$ & EN: B1+3d \\
\hline $\begin{array}{l}\text { Teucrium edetanum M.B. Crespo \& } \\
\text { al. }\end{array}$ & VU: D2 & CONVOLVULÁCEAS & \\
\hline Thymus willkommii Ronninger & VU: D2 & $\begin{array}{l}\text { Convolvulus valentinus Cav. subsp. } \\
\text { valentinus }\end{array}$ & VU: A1c, D2 \\
\hline
\end{tabular}

Fuente: Ministerio de Medio Ambiente. Elaboración propia.EX, extinto; CR, en peligro crítico; EN, en peligro; VU, vulnerable; DD, datos insuficientes; A, reducción de la población (A1, observada o estimada; A2, proyectada); $\mathrm{B}$, de distribución pequeña (B1), reducción de la población (B2) y fluctuaciones (B3); C, población pequeña y reducción en el número de individuos maduros (rápida, $\mathrm{C} 1$, continua, $\mathrm{C} 2$ ); $\mathrm{D}$, población muy pequeña o restringida; $\mathrm{E}$, análisis cuantitativo de existencia en estado silvestre; $a$, observación directa; b, índice de abundancia de la UICN; c, reducción del área de ocupación, extensión de presencia y/o calidad del hábitat; d, niveles de explotación reales o potenciales; e, efectos de táxones introducidos, hibridación, patógenos,... 


\begin{tabular}{|c|c|c|}
\hline \multicolumn{3}{|c|}{$\begin{array}{c}\text { Cuadro } 11 \\
\text { ESPECIES VEGETALES VALENCIANAS RECOGIDAS EN LA ORDEN DE PROTECCIÓN DE } \\
\text { FLORA ENDÉMICA O AMENAZADA (1985) }\end{array}$} \\
\hline $\begin{array}{l}\text { Protección } \\
\text { total } \\
\text { (Anexo I) }\end{array}$ & $\begin{array}{l}\text { Antirrhinum valentinum Font Quer ssp } \\
\text { valentinum } \\
\text { Asperula paui ssp dianensis (Font Quer) Romo } \\
\text { Bupleurum gibraltaricum Lam } \\
\text { Celsia valentina } \mathrm{L} \text {. } \\
\text { Cistus incanus } \\
\text { Convolvulus valentinus Cav. ssp valentinus } \\
\text { Cynomorium coccineum L. } \\
\text { Chaenorrhinum tenellum (Cav) Lange } \\
\text { Genista lucida Lamb } \\
\text { Helianthemum caput-felis Boiss } \\
\text { Hippocrepis valentina Boiss }\end{array}$ & $\begin{array}{l}\text { Ilex aquifolium } \mathrm{L} \\
\text { Juniperus oxycedrus ssp macrocarpa }(\mathrm{Sm}) \text { Ball } \\
\text { Leucojum valentinum } \text { Pau } \\
\text { Limonium cavanilesii Erben } \\
\text { Limonium dufourii (Girard) } \\
\text { Petrocoptis pardoi } \text { Pau } \\
\text { Saxifraga longifolia } \text { Lapeyr } \\
\text { Sideritis glauca } \text { Cav. } \\
\text { Silene diclinis } \text { (Lag.) } \\
\text { Teucrium hifacense Pau } \\
\text { Thymus inodorus } \text { Resf. }\end{array}$ \\
\hline $\begin{array}{l}\text { Protección } \\
\text { intermedia } \\
\text { (Anexo II) }\end{array}$ & $\begin{array}{l}\text { Anthyllis lagascana ssp valentina (Esteve) O. } \\
\text { Bolós \& Vigo } \\
\text { Artemisia assoana Willk Benedí } \\
\text { Daphne oleoides Schreb. ssp hispanica (Pau) } \\
\text { Rivas Mart. } \\
\text { Hypericum androsaemum L } \\
\text { Juniperus thurifera L } \\
\text { Lathyrus tremolsianus } \text { Pau }\end{array}$ & $\begin{array}{l}\text { Laurus nobilis } \mathrm{L} \\
\text { Lonicera splendida Boiss } \\
\text { Prunus prostrata Labill } \\
\text { Ruscus aculeatus } \mathrm{L}(\mathrm{K} .) \\
\text { Scabiosa saxatilis } \mathrm{Cav} \\
\text { Taxus baccata } \mathrm{L} \\
\text { Viburnum tinus } \mathrm{L}\end{array}$ \\
\hline $\begin{array}{l}\text { Previa } \\
\text { autorización } \\
\text { para la } \\
\text { recolección } \\
\text { (Anexo III) }\end{array}$ & $\begin{array}{l}\text { Arbutus unedo L. } \\
\text { Arctostaphylos uva-ursi (L.) Spreng. } \\
\text { Astragalus hispanicus Coss ex Bunge } \\
\text { Buxus sempervirens } \mathrm{L} \text {. } \\
\text { Cytisus heterochrous Webb ex Colmeiro } \\
\text { Chamaerops humilis } \mathrm{L} \text {. } \\
\text { Dictamus hispanicus Webb. ex Willk. } \\
\text { Fraxinus ornus } \mathrm{L} \\
\text { Hypericum ericoides } \mathrm{L} \\
\text { Chiliadenus glutinosa }(\mathrm{L} \text {.) Fourr } \\
\text { Lavandula dentata } \mathrm{L} \\
\text { Lavandula multifida } \mathrm{L} \\
\text { Medicago citrina } \text { (Font Quer) Greuther } \\
\text { Micromeria fruticosa }(\mathrm{l}) \text { Druce } \\
\text { Myrtus communis } \mathrm{L}\end{array}$ & $\begin{array}{l}\text { Pistacia terebinthus } \mathrm{L} \\
\text { Sanguisorba ancistroides (Desf) A.Braun ssp } \\
\text { parviflora (Pomel) O. Bolós \& al. } \\
\text { Quercus cerrioides Willk \& Costa } \\
\text { Quercus ilex } \mathrm{L} \\
\text { Quercus pyrenaica Willd } \\
\text { Quercus ilex L. ssp rotundifolia (Lam) Schawrtz } \\
\text { ex T. Morais } \\
\text { Quercus suber L } \\
\text { Quercus faginea L. } \\
\text { Saxifraga cuneata Willd ssp paniculata (Pau) } \\
\text { Mateo \& M.B. Crespo } \\
\text { Sideritis sp } \\
\text { Teucrium sp } \\
\text { Thymus sp }\end{array}$ \\
\hline
\end{tabular}

Fuente: Orden de 20 de diciembre de 1985 de la Conselleria de Agricultura y Pesca, sobre protección de especies endémicas o amenazadas (DOGV no 336). Elaboración propia.

en el que, dependiendo del peligro o interés de cada una de ellas, se llevarán a cabo diferentes planes de recuperación, protección y/o conservación.

Si hacemos una revisión de las especies vegetales incluidas en los cuatro catálogos florísticos vigentes: Directiva de Hábitats, Catálogo Nacional de Especies Amenazadas, Lista roja nacional de flora vascular amenazada y el listado de la Orden de protección de flora 


\section{Cuadro 12 \\ LISTA ROJA Y PROPUESTA DE PROTECCIÓN LEGAL PARA LA FLORA VASCULAR \\ VALENCIANA EXTINTA Y AMENAZADA, \% \\ (E. Laguna, B. Pérez Rocher, C. Fabregat, J.J. Herrero Borgoñón, L. Serra)}

\begin{tabular}{|l|c|}
\hline Extintas en estado silvestre (EW) & 5.3 \\
En peligro crítico (CR) & 16.4 \\
En peligro (EN) & 12.4 \\
Vulnerables (VU) & 65.8 \\
\hline
\end{tabular}

Leyenda: EW, endemismo extinto en estado silvestre; CR, amenazado en peligro crítico; EN, en peligro; VU, vulnerable. Fte.: LAGUNA LUMBRERAS, E. (coord.) (1998): Flora endémica, rara o amenazada de la Comunidad Valenciana. Consellería de Medio Ambiente. Generalitat Valenciana. Valencia, pág. 372.

endémica amenazada de la Generalitat Valenciana, y tomamos únicamente los endemismos valencianos e ibéricos amenazados, se observa que representan el $32.6 \%$ del total. Si además, agrupamos estos táxones por grado de endemicidad y les aplicamos las categorías de la UICN (1994), la mayor parte se incluyen dentro de los endemismos exclusivos valencianos y de los compartidos de área global muy restringida, que se corresponden fundamentalmente a hábitats de litoral y de asomos rocosos calizos, por ser espacios donde las condiciones del medio son más extremas y, por lo tanto, de una mayor fragilidad, sobre todo en áreas costeras de nuestra comunidad donde la actividad turística es una clara amenaza (Cuadro 13). Por este motivo, es necesaria una protección mayor de estas especies vegetales desde el propio gobierno de la Comunidad Valenciana.

\section{Conclusiones}

Desde la entrada de España a la entonces CEE, se produce un gran avance legislativo y de actuaciones políticas para la protección de espacios naturales con valor florístico y faunístico, hecho que queda reflejado también a nivel autonómico. La Comunidad Valenciana es uno de los ejemplos más claros dentro del ámbito nacional, sobre todo a partir de la década de los noventa.

En general, se puede afirmar que, si bien el marco legal español es amplio, existen lagunas en algunos aspectos y, sobre todo, su puesta en práctica refleja deficiencias, como pueden ser:

- La escasa compatibilidad entre calificación del suelo y nivel de protección medioambiental en muchos espacios protegidos, en los que tampoco queda claro su límite, de modo que se ven sometidos a fuertes presiones por parte de actividades, sobre todo urbanísticas, que crean tensiones territoriales.

- La falta de coherencia y homogeneidad de criterios entre Estado y CC.AA. a la hora de establecer las figuras de protección, que resultan numerosas y, en muchas ocasiones, reúnen características similares pero reciben denominaciones diferentes.

- El desequilibrio del número de zonas protegidas existente entre CC.AA. y los diferentes intereses que promueven sus promulgaciones como tales, en ocasiones, más que proteccionistas, puramente económicos. 
Cuadro 13

RESUMEN DE LOS CATÁLOGOS Y LISTAS DE FLORA ENDÉMICA AMENAZADA DE LA COMUNIDAD VALENCIANA

\begin{tabular}{|c|c|c|}
\hline Grado de endemicidad & Hábitat & Categoría UICN \\
\hline \multicolumn{3}{|l|}{ Endemismos exclusivos } \\
\hline Limonium duforii (Girard) Kuntze & Roq. sal. lit. & $\mathrm{CR}$ \\
\hline Silene diclinis (Lag.) M. Laínz & Orla bosq. & \multirow{3}{*}{ EN } \\
\hline Thymus webbianus Rouy & Mat. cal. lit. & \\
\hline Verbascum fontqueri Benedí \& J.M. Monts. & Mat.past.sec. & \\
\hline \multicolumn{3}{|l|}{ Endemismos casi exclusivos o compartidos de área global muy restringida } \\
\hline Silene hifacensis Rouy ex Willk. & Roq. cal. lit. & \multirow{3}{*}{$\mathrm{CR}$} \\
\hline Medicago citrina (Font Quer) Greuter & Mat. nitr. lit. & \\
\hline $\begin{array}{l}\text { Cistus heterophyllus ssp carthaginensis (pau) M.B. } \\
\text { Crespo \& G. Mateo }\end{array}$ & Mat. sec. lit. & \\
\hline Linaria orbensis Carretero \& Boira & Cult. past. sec. anu. & \multirow{2}{*}{ EN } \\
\hline Diplotaxis ibicensis (Pau) Gómez-Campo & Mat cost. & \\
\hline \multicolumn{3}{|l|}{ Endemismos ibéricos } \\
\hline Marsilea batardae Launert. & Acuát. herb. húm. & EW \\
\hline Lepidum cardamines $\mathrm{L}$. & Mat. gips. sal. & \multirow{2}{*}{ EN } \\
\hline Euphorbia nevadensis Boiss \& Rent. ssp nevadensis & Past. mont. & \\
\hline \multicolumn{3}{|l|}{ Endemismos dudosos de su presencia en la C.V. } \\
\hline Anthyllis lagascana ssp valentina (Esteve) O. Bolós \& Vigo & Mat. sec. & EN \\
\hline
\end{tabular}

Leyenda: EW, endemismo extinto en estado silvestre; CR, amenazado en peligro crítico; EN, en peligro; VU, vulnerable. Fte.: CRESPO VILLALBA, M.B. (2000): «Diversidad vegetal de la Comunidad valenciana: flora vascular de interés», Cuadernos de Biodiversidad, Universidad de Alicante. Ministerio de Medio Ambiente: Orden de 20 de diciembre de 1985 de la Conselleria de Agricultura y Pesca, sobre protección de especies endémicas o amenazadas (DOGV n 336 ). MATEO, G. y CRESPO, M.B. (1990): Claves para la flora valenciana, Editorial del Cenia al Segura, Valencia. LAGUNA LUMBRERAS, E. (coord.) (1998): Flora endémica, rara o amenazada de la Comunidad Valenciana, Consellería de Medio Ambiente, Generalitat Valenciana, Valencia. Elaboración propia.

- La Red Nacional de Espacios Protegidos ha de completarse antes del año 2004 para formar parte de la Red Natura 2000; dentro de los objetivos propuestos se incluye establecer corredores biológicos entre estas áreas, intención sólo iniciada por algunas CC.AA. En parte, se debe a la complejidad que supone crear estos pasillos en zonas con elevada ocupación humana, donde los espacios naturales son, en realidad, islotes de protección.

- Es necesaria una mayor agilidad legal a la hora de redactar y aprobar los Planes de Ordenación y Gestión de los Espacios Naturales Protegidos, aunque, en la mayoría de las ocasiones, dicha ralentización se debe a la conflictividad de intereses, como puede ser presión urbanística o la oposición social de los particulares que ven sus tierras protegidas por una de estas figuras, pese a que pueda revertir en beneficio a estas áreas rurales a través de nuevas infraestructuras, equipamientos. 
- Existe un cierto peligro a que los espacios protegidos acaben como zonas de ocio y recreo, más que laboratorios de investigación o áreas donde se conserve un paisaje natural con una flora y fauna de interés ecológico, motivado por la búsqueda del beneficio económico.

- Es precisa la realización de inventarios forestales, así como la promulgación de una Ley forestal nacional y de unas directrices generales para la ejecución de las repoblaciones, ya que son inexistentes en muchas CC.AA.

- A escala de especie vegetal, hasta fecha reciente, existía la necesidad de ajustar las categorías de protección de flora del Catálogo Nacional con las de la UICN, parcialmente subsanado con la publicación en mayo de 2001 de la Lista Roja de Flora Vascular Amenazada. De todos modos, todavía resulta insuficiente, puesto que no recoge todos los táxones con claro riesgo de desaparición o de reducción de su área de distribución, por lo que ha de ampliarse o completarse con las que se vayan aprobando en las autonomías.

- Es urgente una mayor regulación legislativa ante la entrada de especies exóticas o foráneas que pueden llegar a ser grandes competidoras de las poblaciones autóctonas.

Se puede considerar a la legislación ambiental de la C.V. como una de las más desarrolladas de España, sobre todo en lo referido a la protección de la especie vegetal; pero al igual que en el caso anterior, se advierten algunas deficiencias que son expuestas a continuación:

- Desequilibrio territorial en el número y superficie protegida dentro de la C.V.

- En general, es necesario un sistema de vigilancia, seguimiento y control de las áreas y especies vegetales protegidas, sobre todo de las microrreservas vegetales, en parte justificado por el mayor conocimiento que se tiene de esta figura tras el trabajo de campo realizado.

- Respecto a esta figura de protección, existen algunas limitaciones como son la declaración de áreas de interés florístico en propiedad privada y en el litoral debido a la gran presión de consumo de suelo por parte del turismo.

- Si se tiene en cuenta el número de taxones exclusivos valencianos con la categoría de amenazados (UICN, 1994) que se localizan exclusivamente en el litoral, unos 17, se observa que son más de la mitad y que, prácticamente en su totalidad, se centran en la costa alicantina, sobre todo en los acantilados. No hay que olvidar que es precisamente esta provincia la que mayor desarrollo turístico alberga, concentrado en esa franja costera. La conflictividad de intereses entre lo económico y la protección de la flora es evidente en estos sectores donde, por lo general, la balanza se inclina hacia el primero.

- Existen contradicciones entre los catálogos y listas de flora nacionales y valencianos, debido a los diferentes criterios utilizados; el caso más evidente es el de la Orden de 1985, promulgada por la Consellería de Agricultura y Pesca de la C.V., donde prima el interés de aprovechamiento comercial de estas especies.

- Es imperiosa la redacción del Catálogo Valenciano de Especies Amenazadas por la Generalitat Valenciana, con el fin de unificar criterios ante la extensa gama ofrecida desde otros organismos, y agrupar en una sola lista toda la flora que reúna estas características, teniendo en cuenta que especies que no son endémicas pueden ser raras dentro del ámbito valenciano, aunque no en otras zonas, y merecer protección legal. 


\section{Bibliografía}

BOX AMORÓS, M. y MARCO MOLINA, J.A. (1991): «Espacios protegidos» Atlas Temático. Comunidad Valenciana, $\mathrm{n}^{\circ}$ 10, Editorial Prensa Alicantina S.A. Alicante, pp. 181-200.

CANCER POMAR, L. (1995): «Una lectura geográfica de las bases legales para la protección de los paisajes. El marco general de España y el particular de Aragón» Intervenir el territorio: planificación y gestión. Boletín de la Asociación de Geógrafos Españoles, $\mathrm{n}^{\mathrm{o}}$ 20, pp. 101-114.

CRESPO VILLALBA, M.B. (2000): «Diversidad vegetal de la Comunidad valenciana: flora vascular de interés». Cuadernos de Biodiversidad. Universidad de Alicante.

CRUZ OROZCO, J. y SUCH CLIMENT, MP.: «Los espacios protegidos». Geografía del País Valenciano. Ed. Ariel. (en prensa)

DE TERÁN, M. (1966): «La ética de conservación y protección de la Naturaleza» en Homenaje al Excmo. Sr. D. Amando de Melón y ruiz de Gordejuela. Inst. de Estudios Pirenaicos-Inst. «Juan Sebastián Elcano» de Geografía. Zaragoza, pp. 69-76.

HERNÁNDEZ HERNÁNDEZ, Ma (1998): «Repercusiones socio-espaciales de la reforestación de tierras agrícolas en la provincia de Alicante», IX Coloquio de Geografía Rural. Universidad del País Vasco-AGE, pp. 251-257.

MATEO, G. y CRESPO, M.B. (1990): Claves para la flora valenciana. Editorial Del Cenia al Segura. Valencia.

MINISTERIO DE MEDIO AMBIENTE (2000): Estrategia Española para la conservación y el uso sostenible de la diversidad biológica.

LAGUNA LUMBRERAS, E. (coord.) (1998): Flora endémica, rara o amenazada de la Comunidad Valenciana. Consellería de Medio Ambiente. Generalitat Valenciana. Valencia.

PADILLA, A. y RAMÓN, A. (1997): «Planeamiento ambiental a escala de detalle: microrreservas de flora en la Comunidad Valenciana», Investigaciones Geográficas, enerojunio, ${ }^{\circ}$ 17, Universidad de Alicante, pp. 117-128.

SANZ HERRAIZ, C. y MOLINA HOLGADO, P. (2001): «Espacios naturales protegidos y conservación del medio», en GIL OLCINA, A. y GÓMEZ MENDOZA, J. (coord.): Geografía de España, Ariel Geografía, Barcelona.

TROITIÑO VINUESA, M.A. (1995): «Espacios naturales protegidos y desarrollo rural: una relación territorial conflictiva», Intervenir el territorio: planificación y gestión. Boletín de la Asociación de Geógrafos Españoles, nº 20, pp. 23-38. 